\title{
¿Cuán utópica es la Calípolis de Platón? \\ Reflexiones sobre la "ciudad ideal" y el valor del paradigma en la explicación filosófica
}

\author{
How utopian is the Callipolis of Plato? \\ Reflections on the "ideal city" and the value \\ of the paradigm in the philosophical explanation
}

\author{
MARCELO D. BOERI \\ Pontificia Universidad Católica de Chile \\ mboeric@uc.cl
}

Recibido: 16/05/2017 - Aceptado: 15/09/2017

DOI: https://doi.org/10.20318/fons.2017.3854

\begin{abstract}
Resumen. Uno de los rasgos clave de cualquier proyecto utópico es que no es realizable. Si la ciudad justa platónica es un modelo utópico, no es realizable. Pero Platón afirma que su ciudad es posible. En este artículo argumento que el sentido de "posible" en el que Platón está pensando puede comprenderse mejor si se lo asocia a la tesis de que la ciudad justa de la República es un modelo. Si es un modelo (y si dicho modelo coincide con la Forma de justicia, que puede ejemplificarse en la ciudad empírica), lo que existe en la "realidad" debe ser lo que se aproxima lo más posible al modelo. Esta es la explicación habitual que Platón da cuando relaciona un modelo con su copia: aun cuando el modelo y la copia son hasta cierto punto estructuras simétricas, no son completamente isomórficas. Si lo fueran, un modelo no podría distinguirse de su copia.
\end{abstract}

Palabras clave: Platón, ciudad justa, modelo, utopía

\begin{abstract}
One of the key features of any utopian project is that it is not realizable. If the Platonic just city is a utopian model, it is not realizable. But Plato maintains that his city is possible. In this paper I argue that the sense of 'possible' Plato is thinking of can be better grasped if it is associated with the view that the just city of the Republic is a model. If it is a model (and if such a model coincides with the Form of justice, which can be instantiated in the empirical city), what exists in 'reality' must be what approximates as closely as possible to the model. This is the usual account Plato provides when he relates a model to its copy: even though the model and the copy are to some extent symmetric structures, they are not entirely isomorphic. If they were, a model could not be distinguished from its copy.
\end{abstract}

Keywords: Plato, just city, model, utopia

П НГ Н / F O N S II (2017), 9-25

ISSN 2445-2297 www.uc3m.es/pege
M.D. BOERI, ¿Cuán utópica es la Calípolis de Platón? DOI https://doi.org/10.20318/fons.2017.3854 


\section{Introducción: proyecto político y utopía en Platón}

Desde que Thomas More evocara la República (Rep.) platónica en su tratado Acerca del mejor estado de una República y acerca de la Nueva Isla Utopia (1516), ha habido una tendencia a pensar en el proyecto filosófico-político de Platón como en un proyecto "utópico", donde "utópico" significa "irrealizable"1. En su uso habitual el adjetivo "utópico" y el sustantivo "utopía" se refieren a algo imaginario o ilusorio que no está en ningún lugar y no puede sino ser algo imposible de realizar. Si el modelo platónico de sociedad justa es solamente algo imaginario o ficticio, una característica distintiva de cualquier utopía ${ }^{2}$, el modelo filosófico-político de Rep. no es "realizable". Si el modelo pudiera replicarse en todos sus detalles, no habría ninguna necesidad de modificarlo: las relaciones entre los individuos serían armónicas, cada uno hará lo que debe hacer, la vida de las personas será feliz, las normas e instituciones serán estables y no precisarán de ninguna corrección ${ }^{3}$.

Una versión anterior de este texto fue presentada en el Instituto de Filosofía de la Universidad de Buenos Aires en junio de 2017. Agradezco la invitación del Profesor Francisco Bertelloni y los comentarios del auditorio. Este artículo es un resultado parcial del Proyecto Fondecyt 1150067 (Chile).

${ }^{1}$ Algunos estudiosos de la Utopía de More incluso han llegado a sugerir que la frase platónica $\gamma \tilde{\eta} s$

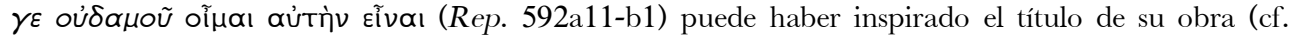
LOGAN 1983, p. 130 n. 2, citando a Nagel y Kristeller). Las diferencias entre la Rep. platónica y la Utopía de More son, de todos modos, notables (la construcción de More parte de un principio económico, la de Platón de uno moral; la Utopía de More es un estado igualitario, la ciudad de Platón no lo es); además, como observa Logan 1983, pp. 138 ss., la dependencia de More de la Política de Aristóteles es importante.

${ }^{2}$ Cf. DAVIS 1985, p. 22 n. 1. Algunos teóricos especifican que cuando los proyectos políticos hacen un intento por convertir la ficción que describen en hechos dejan de ser utopías (DAVIS 1985, p. 24). Desde esta perspectiva, la Rep. de Platón no puede ser una utopía. La condición de impracticabilidad es común en cualquier utopía; pero no es claro qué significa impracticable, pues puede querer decir algo que no puede llevarse a la práctica sin más, o algo que fue adoptado y aplicado pero que, finalmente, no resultó como se esperaba (cf. DAVIS 1985, p. 23). Laks propone distinguir entre posibilidad lógica y real, distinción en la que aquel tipo de posibilidad corresponde a una realidad de derecho, y ésta a una realidad (o "realización") empírica (2012, pp. 25-26). Si para Platón la "mejor polis" de hecho existente no puede ser más que una réplica o copia del modelo de ciudad justa, el filósofo-rey no puede ser "posible" en el sentido de "posibilidad real" (i.e. de "realización empírica", esto es, en el sentido de que sea posible replicar con exactitud el modelo). Si un paradigma coincide con una Forma (cf. Platón: Eutifrón 6e4-5; Parménides 132d2), no puede ser replicado con exactitud. Es cierto que hay razones para pensar que no hay una Forma de polis o de politeía (bastaría con la Forma de justicia; cf. BuRnYeAT 1999, p. 298; VegETti 2000, p. 119; KLOSKo 2006, pp. 181-182), pero si la polis justa de la Rep. es un modelo, la réplica siempre se "queda corta" respecto de su modelo. Regreso a este problema en los párrafos 2-3.

${ }^{3}$ Algunos de estos rasgos son habitualmente descritos como parte de la caracterización de una utopía como género literario (cf. Lisi 2012, p. 10; ZuOLO 2012, pp. 40-41). Para los diversos significados de la noción de "utopía” cf. LisI 2012b, pp. 80-82. ZUOLO 2012 propone reemplazar el concepto de "utopía" para calificar el proyecto político de Platón por el de "teoría ideal normativa" 
A veces se argumenta que aquello de lo que habla Platón en su Rep. no puede entenderse como una organización política real ni tomarse como un proyecto político que pueda ser realmente entendido como tal. En ese marco de discusión se afirma que las secciones más políticas de la Rep. no pueden entenderse más que como una metáfora del estado interno del alma individual (cuyo único propósito sería la formación moral del sujeto) y que el individuo justo platónico sólo podría vivir alejado de la política real. De acuerdo con este tipo de enfoque la Rep. no constituiría una obra de filosofía política ${ }^{4}$. Pero este tipo de interpretación parte de premisas que Platón probablemente no habría aceptado y deriva del prejuicio de que la ética y la política son dominios distintos. No hay duda de que para Platón no es tan clara, como lo es para nosotros, la demarcación entre ética y política, de modo que para él no debe haber sido tan obvio que pueda haber una verdadera organización política en la que la calidad moral de sus gobernantes sea irrelevantes.

Un filósofo político contemporáneo puede tener serias dudas respecto de si la Rep. constituye un genuino "tratado" de filosofía política: qué tiene que hacer, podría preguntar, en una supuesta discusión de filosofía política un examen de los poderes cognitivos y sus correspondientes objetos en el "viaje del alma" desde la oscuridad a la claridad epistémica en la línea dividida de Rep. VI. Pero eso solamente puede ser un prejuicio nuestro que si se conserva introduce más dificultades que soluciones. Hay buenas razones para pensar que la búsqueda incesante de Sócrates de la virtud o excelencia (ápєtń) no es solamente un ejercicio teóricodefinicional que no tiene nada que ver con la acción en general y con la acción política en particular. Platón recuerda a Sócrates como un modelo de "verdadero político"; en Gorgias 521d6-e2 el personaje Sócrates afirma que se cuenta entre uno de los pocos atenienses - «por no decir el único» - que se dedica al «verdadero arte

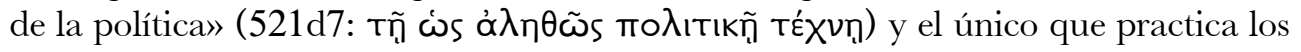
asuntos políticos entre sus contemporáneos. Sus argumentos, son «en vista de lo mejor y no de lo más placentero». Esto seguramente es así porque su propósito es dar con la "virtud", es decir, con lo mejor. Pero no sólo se trata de la virtud entendida como el estado interno del alma individual, sino también como la condi-

\footnotetext{
${ }^{4}$ Cf. AnNas 1997, pp. 145, 152 (citada por Vegetti 2000, p. 114 n.17) y 1999, cap. 4, esp. 8182. Rosen 2005, pp. 49, 79. Para un enfoque diferente cf. LAKS 2007, cap. 2, quien argumenta que Platón delineó "los contornos de la filosofía política"

5 Sobre este importante detalle cf. KOYRÉ 1945, p. 71 (citado por SchOFIELd 2006, p. 48); VEgETTI 2000, pp. 144-145. Schofield detecta una “tensión” entre filosofía y política (por no decir entre ética y política) que permea el pensamiento de Platón (cf. su 2006, p. 48 n. 50). En realidad, esa "tensión" no es de Platón, sino de Schofield que, como casi todos nosotros, no puede sino encontrar un contraste entre ética y política (contraste en el que la ética se encuentra habitualmente del lado normativo y la política del descriptivo en el sentido de que describe lo que de hecho ocurre).
} 
ción individual que no puede practicarse si no es en relación con los demás miembros de la comunidad.

Este pasaje, que muestra que la filosofía moral del Sócrates platónico era también filosofía política, es útil para advertir por qué en el proyecto platónico de ciudad justa el estado interno del alma individual también es relevante en sentido político. Cuando en Rep. VIII Platón analiza las formas corruptas de gobierno subraya con especial énfasis que los diferentes tipos de ciudad y las consiguientes formas de gobierno dependen directamente de los tipos de personas que los habitan y, en especial, de los tipos de personas que ejercen el poder político (cf. 544d-e). Cuantos sean los "modos de gobierno", distintos en su género, tantos serán los "modos de alma". Si esto es así, Platón no puede haber pensado que hay un hiato entre la acción política de un gobernante y el tipo de persona que el gobernante es en términos morales. Algunos de estos pasajes platónicos son los que dan lugar a las interpretaciones que sostienen que las partes más políticas de la Rep. no tienen en cuenta la "realidad política" y las propuestas políticas de Platón, si se las toma literalmente, son sencillamente absurdas? .

Aunque los requisitos platónicos de una buena organización política se consideren ingenuos y como un ejercicio dialéctico cuyo objetivo es producir una formación moral del individuo, es claro que el tipo de examen que Platón lleva a cabo en Rep. no tiene nada de ingenuo y no se limita a la formación moral de la persona en el sentido de una preocupación de tipo exclusivamente moral: los textos no sólo muestran que no es cierto que él entienda su proyecto solamente como "una metáfora del estado interno del alma individual”, sino que además apuntan a la necesidad de exigir la honestidad como una condición esencial del gobernante. Esto puede parecer una perogrullada, pero no es difícil advertir que, por trivial que resulte, constituye, incluso para nosotros, una condición esencial del buen gobernante. Explícita o implícitamente esperamos que los gobernantes reúnan dos condiciones básicas: (i) que sean competentes en un sentido técnico y (ii) que sean probos en sentido moral.

Si la ciudad justa platónica es un modelo utópico, se dice, no es realizable. Pero Platón sostiene que su ciudad es posible (i.e. realizable) ${ }^{8}$. Sugeriré que una estrategia apropiada para comprender el sentido en que Platón cree que su proyecto es "posible” es asociar esa noción a la tesis de que la ciudad justa es un modelo. El modelo

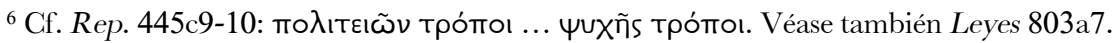

${ }^{7}$ Éste es el enfoque de Annas; un completo resumen de la interpretación de Annas y otras similares es proporcionado por VEGETTI 2013, pp. 4-6.

${ }^{8}$ Como señala Zuolo, aun cuando el carácter de irrealizable de una utopía refleja un aspecto básico del término "utopía", la dificultad de este aspecto yace en el hecho de que no hay acuerdo respecto de qué debe entenderse por "realizable" (cf. su 2012, p. 41; véase también DAVIS 1985, pp. 16-17; 368369: LAKS 2007, p. 104).
} 
de ciudad justa debe coincidir con la Forma de justicia; si esto es así, lo que existe en la "realidad" debe ser lo que se aproxima en mayor grado al modelo. Esta es la explicación que Platón suele dar cuando relaciona un modelo con su copia: aun cuando el modelo y la copia son hasta cierto punto estructuras simétricas, no son completamente isomórficas. Discutiré brevemente el modo en que Platón identifica su explicación de su ciudad buena con un modelo (Rep. 472c4 ss.) y argumentaré que su estrategia sigue su práctica habitual de valerse de paradigmas como dispositivos explicativos previos y necesarios en cualquier explicación filosófica de un tema relevante (cf. Político 277d).

Platón no sólo es consciente de las enormes dificultades de llevar a la práctica su proyecto filosófico-político ${ }^{9}$, sino que además cree que es posible realizar dicho proyecto. Si esto es así, la Calípolis platónica no es un modelo utópico por ser "irrealizable". Este tipo de enfoque no es nuevo y ha sido tratado en el pasado por otros estudiosos ${ }^{10}$; sin embargo, en el curso de mi discusión me detendré en algunos otros aspectos de detalle que pueden ser importantes para la comprensión del proyecto platónico. Por ejemplo, (i) a pesar de lo que sugieren algunos intérpretes, Platón no cree que sus guardianes sean "superhombres" o personas incorruptibles; (ii) aunque los guardianes de la Rep. instituyen leyes, no son normas explícitas al modo de una legislación formal o código legal. ${ }^{11}$ En este punto de detalle procuraré mostrar que Platón es coherente en sus tres "obras políticas" (Rep., Político y Leyes) cuando sugiere que la ley es letra muerta sin alguien que posea el conocimiento apropiado para comprender no sólo el contenido prescriptivo de la ley, sino también cómo aplicarla a una situación concreta.

\section{La polis sana y su realización}

De acuerdo con algunas caracterizaciones contemporáneas, una "utopía” designa (i) un proyecto de modificación radical de un orden social existente. Además, (ii) un proyecto "utópico" no pretende reemplazar lo existente, sino hacer una crítica radical de la organización política que se espera reemplazar. (iii) El carácter de abstracto y, especialmente, de irrealizable se convierte así en los atributos

\footnotetext{
9 Proyecto que, según algunos estudiosos, puede entenderse mejor como una "utopía proyectual" (que es diferente de un "programa político"). Cf. VeGETTI 2000, pp. 122-124; FERRARI 2012, p. 104, siguiendo a Vegetti, habla de "teoría proyectual".

${ }^{10}$ Cf. FerRARi 2012, pp. 102-104; LAKs 2012, pp. 20-21; Lisi 1999, pp. 53-57; Lisi 2012b, pp. 82-86; SCHOFIELD 2006; VEGETTI 2000, pp. 117-119.

${ }^{11}$ Entre esas leyes deben contarse las siguientes: (i) aunque los guardianes sean más fuertes que sus gobernados, no deben ser amos salvajes, sino benefactores (Rep. 416b); (ii) deben tener una educación

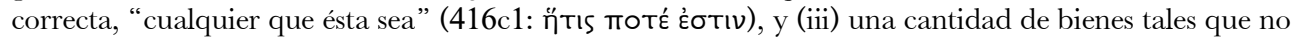
les impidan ser los mejores guardianes ni los inciten a causar daños a los demás ciudadanos; (iv) ningún guardián poseerá bienes privados, con excepción de los bienes básicos necesarios (416c-d). Cf. también los pasajes citados por LAKS 2007, p. 51.
} 
que más frecuentemente se asocian a los modelos utópicos ${ }^{12}$. La noción de utopía suele asociarse al proyecto político de Platón tal como éste es presentado, especialmente, en la Rep. ${ }^{13}$ Según algunos, la de la Rep. es una "visión utópica”, en tanto que la de Leyes es una guía más practicable y aplicable a la acción política efectiva $^{14}$. En Leyes $875 \mathrm{c}-\mathrm{d}$, sin embargo, Platón sigue creyendo que, si hubiese una persona con la capacidad suficiente para gobernar la ciudad, no tendría ninguna necesidad de leyes que lo rigiesen, porque no hay ley ni ordenación alguna que sea superior al conocimiento. Esto no está muy lejos del argumento general de la Rep., donde parece sugerirse que en caso de instaurarse el gobierno de los filósofos no sería necesaria la existencia de un sistema legal en un sentido formal. Bastará con que se apliquen las tres "leyes o previsiones fundamentales" (que coinciden con las "olas") de la ciudad justa: la igualdad entre hombres y mujeres (Rep. 451e-452a; 455d-

${ }^{12}$ Algunas de las características recién mencionadas como propias de una utopía (especialmente su carácter de irrealizabilidad y de cambio socio-político radical) son consideradas por Zuolo en su discusión del tema y la posibilidad de aplicar con propiedad la noción de "utopía” a los rasgos más peculiares del pensamiento político de Platón (ZuOLO 2012, esp. pp. 40-43. Cf. también SchOFIELD 2006, pp. 199, 234-235).

${ }^{13}$ Cf. Popper, quien directamente habla de la "ciudad utópica de la República" o de "ingeniería social utópica" (que se opondría a lo que él denomina "ingeniería social paulatina": «piecemeal social engineering»: cf. especialmente POPPER 1947, pp. 1, 18 y, especialmente, 138-141). Para una discusión pormenorizada de los varios sentidos en que puede entenderse la "utopía platónica" véase VeGETTI 2000, quien hace notar que la polémica de Popper, a pesar de ser "excesiva y presuntuosa", mostraba la evidencia incontestable de la radical extrañeza del pensamiento político de Platón respecto de la tradición liberal-democrática" (p. 111). Una evaluación balanceada, que pone en contexto las motivaciones del proyecto de Popper, puede verse en KLOSKO 2006, pp. 139-142. La tesis de que la

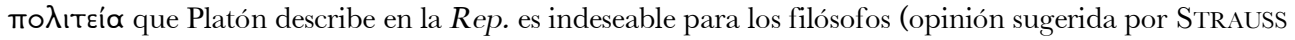
1964, cap. 2 y respaldada en décadas recientes por BLOOM 1991, pp. 346, 368, y por ROSEN 2005, pp. $133,195)$ es una idea que no tiene ningún apoyo en la evidencia textual y que, a mi juicio, no se sigue del argumento platónico. Si lo que Platón propone es una resignificación radical de la política en la que

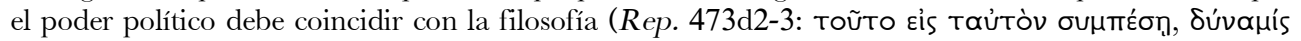

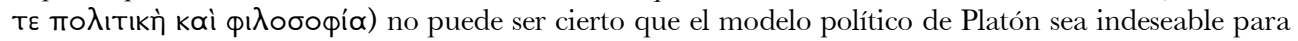
los filósofos. Tampoco puede ser cierto que, en caso de instaurarse el modelo platónico, dicho modelo conllevaría la incómoda consecuencia de que los filósofos se verían obligados a involucrarse en política. Si el modelo platónico puede llevarse a cabo, los filósofos no podrían hacer otra cosa que involucrarse en política, ya que política y filosofia serían lo mismo.

${ }^{14}$ Para este enfoque cf. KRAUT 2010, pp. 60-62. Una discusión crítica de esta posición se encuentra en LISI 1999, pp. 51-57; entre otros puntos de coincidencia entre Rep. y Leyes Lisi señala el hecho de que también las Leyes son «una propuesta de carácter normativo que deberá sufrir adaptaciones en el momento en que se la lleve a la práctica». Además, en Leyes «el segundo mejor sistema político» comparte tres requisitos que ya están presentes en Rep.: la unidad de la ciudad, la amistad entre los ciudadanos y el énfasis del interés común en desmedro del privado (pp. 54-55). Como explícitamente afirma Platón, lo común une ( "dispersa o destruye") las ciudades (Leyes 875a6-7). El requisito de la unidad (fuertemente enfatizado en Rep. 422e-423b, 433d) reaparece en Leyes como una condición básica para la conservación de la ciudad. 
456a), la comunidad de mujeres e hijos (457c-d; Leyes 739c) y, la tercera y mayor de todas las olas, el gobierno de los filósofos $(473 \mathrm{c}-\mathrm{d})$.

Cuando Platón concluye que los males de la humanidad no cesarán hasta que los reyes sean filósofos o los filósofos reyes lo hace creyendo que todas las ciudades actuales están mal gobernadas ${ }^{15}$. Platón se queja de que en la actualidad no hay ninguna ciudad que posea instituciones que sean dignas de una naturaleza filosófica (Rep. 497b1-2). Es claro que la intención de Platón era no sólo llevar a la práctica su proyecto filosófico-político (Rep. 473b, 502c; Carta VII 327a-340a), sino que además albergaba la esperanza de que su proyecto pudiera realizarse. $\mathrm{Y}$, lo que es más importante, creo, es que esa esperanza de llevar a cabo su proyecto filosóficopolítico no era una mera expresión de deseo. Son numerosos los pasajes en los que aclara que la discusión de la cuestión de la posible realización de su modelo político no es algo fácil, pues puede producir muchas dudas y hacer pensar a quien oye su explicación en una mera expresión de deseo ${ }^{16}$. Platón no sólo es consciente de las dificultades que su proyecto tiene en cuanto a su realización; también está dispuesto a abrir el debate respecto de los puntos más difíciles (por ejemplo, si la mujer es capaz de compartir con el hombre todas las tareas o ninguna; cf. Rep. 452e4-5:

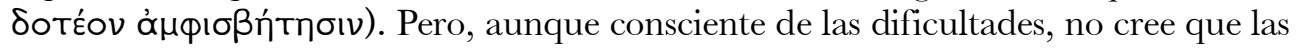
"leyes o previsiones fundamentales" de su modelo de organización política (que lo guardianes del Estado no tengan propiedad privada, 458c-d; la comunidad de mujeres e hijos, 449d, 457c-e, 466c, 543a; que hay mujeres que también pueden tener las cualidades propias de un guardián de la polis, $452 \mathrm{e} 4$ etc.) sean irrealizables en la medida en que "no son contrarias a la naturaleza”. Por el contrario, Platón sugiere que lo que se hace en la actualidad es contrario a la naturaleza (456b-c; véase también 450c-d y, especialmente, 499b-c) y por eso mismo irrealizable, o realizable, pero con los resultados nefastos ya conocidos ${ }^{17}$.

\footnotetext{
${ }^{15}$ Rep. 473c-d; 501e-502c; Carta VII 326a2-b4.

16 Cf. Rep. 450c-d, 456b-c. "Expresión de deseo" o simplemente "deseo" («pio desiderio», como traduce Vegetti 2000, ad loc., «vuoto desiderio», como interpreta FERRARI 2012, p. 103) es el giro que suele usarse para traducir el griego eủxń (cf. EGGERs LAN 1986 ad loc.; «wishful thinking», REEVE 2004, ad loc.). La palabra significa "plegaria" (así traduce BlOOM 1991, ad loc.), pero también "aspiración".

${ }^{17}$ Éste y otros pasajes similares (cf. 456b-c, 499c) muestran lo alejado del texto platónico que están ciertas afirmaciones de Strauss, quien concluye con cierta ligereza que la ciudad justa es imposible porque «está en contra de la naturaleza», ya que la igualdad de sexos y el comunismo absolutos son contra naturaleza (cf. su 1964, p. 127). El pasaje de Platón citado y comentado arriba dice exactamente lo contrario. Es claro que Strauss debe estar pensando en lo que su sentido común (no el de Platón) entiende por "naturaleza" para hacer este tipo de observación. Probablemente, en época de Platón pasaba algo similar a lo que piensa Strauss; eso explica que Platón se detenga a explicar en qué sentido piensa que no hay una diferencia radical de naturaleza entre mujer y varón.
} 
En Rep. VII Platón concluye que quienes tengan naturalezas de guardianes, hayan sido capaces de sortear todas las pruebas a las que se los someta y hayan resultado ser los mejores ("tanto en los hechos como en las ciencias"; 540a6), deben

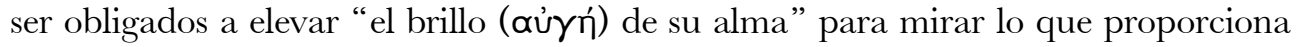
luz a todas las cosas (i.e. la Forma o Idea del Bien), y luego de ver el Bien en sí y de

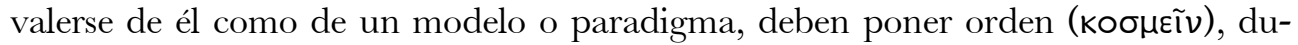
rante el resto de sus vidas y por turnos, en la polis. Platón nos recuerda que, si un guardián intenta ser feliz "de una manera tal que deje de ser un guardián”, entonces ya no valorará un modo de vida mesurado e intentará apropiarse de lo que le pertenece a la ciudad (Rep. 466b). Es también por eso que los guardianes no deben poseer riquezas: si tuvieran más del mínimo necesario de propiedad, terminarían siendo administradores de sus propiedades y no estarían interesados en conservar lo público, sino sólo lo privado (417a-b). Los guardianes no necesitan el oro y la plata que proviene de los hombres pues siempre tienen en sus almas el que procede de los dioses (416e5-6), comenta Platón de un modo un poco irónico. El oro mortal

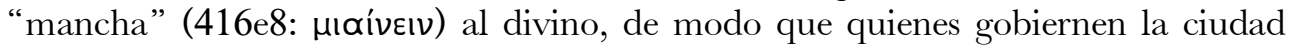
deberán evitar todo contacto con el dinero (416d-417a).

Estos pasajes muestran que, aunque los "perfectos guardianes" (Rep. 428d; 503b) son personas excepcionales (tanto desde el punto de vista de sus talentos naturales como desde el de sus esfuerzos personales para lograr activar en la dirección correcta dichos talentos), no son seres perfectos ni incorruptibles y, en ese sentido, no son "abstracciones" ${ }^{18}$. Platón no $\mathrm{cree}^{19}$ que las personas que habitarán su ciudad deban ser "superhombres" o dioses; estos rótulos ni siquiera pueden aplicarse a quienes, después de la estricta selección descrita arriba, resulten ser los guardianes de la ciudad. Esto prueba que Platón no cree que sus guardianes sean incorruptibles y, mucho menos que sean "superhombres" o dioses; los guardianes son seres excepcionales, pero son humanos, y si son humanos, son corruptibles. La idea de Platón no sólo es que si los guardianes poseyeran casas, tierras o dinero se convertirían en empresarios y administradores de sus bienes, sino que, al abandonar de esa manera su función específica, violarían otra "ley" básica de la ciudad: el principio de justicia según el cual cada uno debe hacer "lo suyo", es decir, lo que le corresponde según su condición natural (Rep. 370c, 433d-434a, 435b, 441c-d). Según Platón, el dinero es, de suyo, un elemento corruptor, pero en manos de quienes ejercen el poder político (incluso en manos de sus "perfectos guardianes") aumenta su poder corruptor. 44).

${ }^{18}$ Como argumenta More en su Utopía a través de su personaje Rafael (cf. STARNES 1990, pp. 43${ }^{19}$ Como supone Rosen 2005, p. 81. 
Entonces, si la Rep. de Platón se propone una reforma radical del orden político existente y procede a hacer una crítica explícita de los sistemas y prácticas políticas del momento, su modelo político-filosófico puede considerarse una "utopía" ${ }^{20}$. La radicalidad es tan potente que, al hacer coincidir la política con la filosofía, hace que la distinción ley/derecho, por un lado, y poder/política, por el otro, quede desdibujada. Es Platón quien advierte, con toda claridad a mi juicio, que la rectitud nunca está del lado del poder político, pero ésa es, precisamente, la razón por la cual todas las ciudades están mal gobernadas: si lo que es correcto no está del lado del poder político sólo habrá injusticia, separación entre los miembros de la misma comunidad política y por eso mismo destrucción de dicha comunidad ${ }^{21}$. Pero si la posición de Trasímaco fuera razonable, deberíamos contentarnos con dar por sentado que la injusticia no puede erradicarse de las comunidades humanas y que lo único que puede hacerse es establecer relaciones políticas basadas en el uso espurio del poder, no en relaciones cimentadas en un uso correcto de la razón. Es cierto que en un contexto diferente Platón cree que no es posible que los males sean erradicados ("pues siempre debe haber algo contrario al bien"; Teeteto 176a); pero en el marco de Rep. V la idea es que, aun cuando el modelo de polis justa no puede

${ }^{20}$ Esa radicalidad puede verse en las "leyes o previsiones fundamentales" del Estado platónico, pero también en la exigencia de que los gobernantes no tengan contacto con el dinero (una medida que, seguramente, es poco práctica y difícil de aplicar, pero, a la luz de los desatinos a los que nos tienen acostumbrados nuestros políticos, parece que la sugerencia de Platón no es tan desatinada).

${ }^{21}$ La tesis de Trasímaco de la justicia como la conveniencia del más fuerte (Rep. 338c-343c) es ilustrativa para entender por qué en el proyecto político de Platón es decisivo insistir en que no basta con describir lo que de hecho sucede para justificar un orden político. El punto de vista de Trasímaco (o de la ideología que él representa) es privilegiar la facticidad en lo político y en lo moral ("facticidad" entendida en el sentido de que, "de hecho, la justicia es lo que efectivamente es", no lo que debería ser). La posición de Trasímaco tiene la indeseable consecuencia de que, de ser cierta, habrá muchas "formas o especies de justicia” y que lo que es justo en un contexto puede no serlo en otro. Una idea similar, asociada a la tesis protagórea del homo mensura, desarrolla Platón en Teeteto, donde argumenta que si cada ciudad establece como justo y legal lo que le parece que es justo y legal, no habrá nadie más sabio que otro, pero es precisamente en este punto en el que hay consejeros que, en relación con la verdad (172a8: трòs á $\lambda \hat{n} \theta \varepsilon ı \alpha v)$, aventajan a otros, así como hay opiniones que son superiores a otras. Posiciones como las de Protágoras, según Platón, no están dispuestas a avalar que conceptos prácticoevaluativos (como "justo", "honorable", etc.) tengan por naturaleza un ser propio (172b2-5), pero obviamente el Sócrates platónico del diálogo Teeteto sí lo cree. Sobre el énfasis de Trasímaco en la facticidad política ("la justicia en el mundo como es, no en condiciones utópicas") cf. ANNAS 1985, p. 156, quien, sin embargo, reconoce que cuando Platón nos da un esbozo del "ideal” no está desarrollando una imagen completa de una utopía, sino que lo que le interesa es el estado ideal en el sentido del estado idealmente justo. En parte, el enfoque de Trasímaco también es respaldado por Rosen cuando sostiene que «nuestra afirmación de amar la justicia más allá de todo lo demás es una noble mentira» (2005, p. 133). Según Rosen, el gobierno de la filosofía es justo para Platón, pero la ciudad resultante no es la que sería deseable o la que conduciría a la felicidad de sus ciudadanos. Rosen piensa que habría un conflicto entre justicia y felicidad. El desafío de Platón, en realidad, es mostrar que, pace Rosen, no hay tal conflicto y que lo que la gente habitualmente entiende por felicidad no es tal. 
realizarse en los mismos términos en los que se lo formula en el lógos, sí puede realizarse en la medida en que «nos acerquemos lo más posible al paradigma» enunciado en el discurso (Rep. 473a7-8) ${ }^{22}$.

Desde el punto de vista de su radicalidad, el proyecto platónico es utópico. Por otro lado, si un proyecto es utópico porque es de suyo irrealizable, el proyecto no puede calificarse de "utópico", pues, aun admitiendo su dificultad, Platón cree que su proyecto es practicable. Al discutir acerca de la relevancia de educar a los niños y adolescentes en una filosofía que sea apropiada a sus edades (498b), Sócrates señala que esa enseñanza debe adecuarse al desarrollo de la persona, de modo que, cuando el individuo comienza a alcanzar su madurez, deben intensificarse los ejercicios filosóficos acorde a la edad. Se trata de una descripción rápida de la formación de los futuros gobernantes; Platón parece sugerir que a través de este tipo de esfuerzo y de actividad formativa habrá un momento en el que el individuo sea capaz de aunar los aspectos teóricos de su instrucción con los prácticos, un detalle que puede ser decisivo en el perfecto guardián quien debe encontrarse «tan perfectamente como le

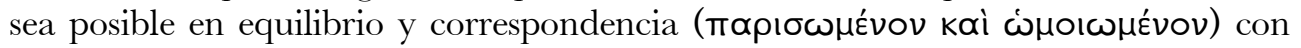

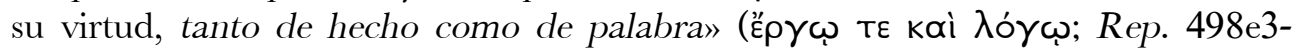
499a2)23. El discurso (o el "relato", como suele decirse en el discurso público de ciertos experimentos políticos y sociales recientes) es relevante, pero para que sea realmente efectivo no debe (aunque de hecho puede) estar divorciado de la acción: si digo A y hago - A se me puede acusar de incoherencia, una acusación que no es percibida como algo grave por parte de quien comete dicha incoherencia (un hecho que se torna particularmente dramático cuando quien comete esa incoherencia está ejerciendo el poder político). Naturalmente, es parte de su engaño hacernos creer que tal incoherencia no es grave, una estrategia ya detectada por Platón como parte del ejercicio espurio del poder. Esta estrategia espuria explota (tal vez conscientemente) el hecho de que, cuando lo terrible se vuelve habitual (cuando "se naturaliza”, como se dice en el discurso público), deja de ser terrible ${ }^{24}$. La objeción de quien hace notar ese tipo de inconsistencia es relevante, precisamente, porque pone de manifiesto el engaño. Pero el engaño está asociado a la falsedad, de modo

\footnotetext{
${ }^{22}$ Según Schofield, en Leyes, a diferencia de la República, Platón se contenta con realizar el ideal a través de "aproximaciones" (cf. su 2006, p. 232). Como es claro, a partir del pasaje de Rep. V recién citado, en este tema no hay diferencia entre Rep. y Leyes.

${ }^{23}$ Cf. Platón, Laques 193d11-e2, donde Sócrates advierte a Laques que están procediendo “al

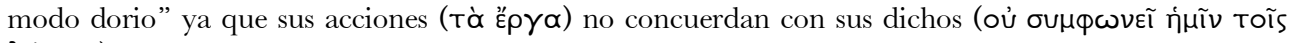

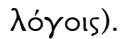

${ }^{24}$ Cuando Platón hace su análisis de las formas corruptas de gobierno y se detiene en la tiranía ("que se apodera de lo ajeno de un solo golpe") muestra que el engaño y la violencia son los medios a los que echa mano quien gobierna tiránicamente (Rep. 344a-b). En este caso no se trata de la "noble mentira" de la que pueden hacer uso los guardianes de la ciudad justa "en beneficio de los gobernados" (Rep. 382c-d; 389b, 414b-c 459b-c. Cf. Leyes 663d-e).
} 
que cuando hay engaño hay apariencias (como enseña Platón en Sofista 268c). Esas apariencias son la "realidad paralela" generada por el "relato", el discurso falso que sirve para producir la parafernalia que necesita el gobernante injusto (es decir, el "no gobernante", visto desde la perspectiva platónica), de modo de seguir engañando a sus gobernados.

¿Qué se puede hacer ante un escenario tan desolador? Platón cree que este tipo de situación puede modificarse a través de "un solo cambio" 25 que permitirá transformar ese estado de cosas, un cambio que, aunque no sea pequeño ni fácil, es, no obstante, posible: que los filósofos sean reyes o los reyes filósofos (Rep. 473d). El gobierno de sus filósofos conllevará el cambio radical de los demás males que aquejan a las ciudades actuales; su modelo es exigente y sin duda Platón es consciente de ello. Por eso declara que, «temerosos ( $\delta \varepsilon \delta i o ́ t \varepsilon \varsigma)$ y forzados por la verdad» (499b1-2), debemos decir que ninguna ciudad, forma de gobierno (то入ıтвía) o, de modo similar, incluso un hombre pueden volverse perfectos hasta que «estos pocos filósofos que en la actualidad no son considerados malvados pero sí inútiles» sean forzados a cuidar de la polis, quiéranlo o no (la idea innovadora de Platón es que deben gobernar quienes no deseen hacerlo); o bien antes de que se dé un «verdadero amor por la verdadera filosofía gracias a una inspiración divina» en los hijos de quienes ahora gobiernan. Ambas alternativas son difíciles, pero no es razonable afirmar ni que una ni que ambas son imposibles, pues si ése fuera el caso solamente se trataría de una mera "expresión de deseo" (499c4-5: ö $\lambda \lambda \omega$ s Eủxaĩs

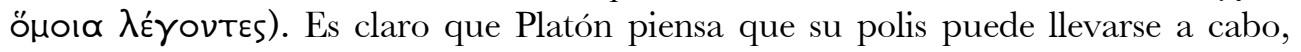
pero también es manifiesto que no cree que se trate de una mera expresión de deseo: uno puede desear lo que guste, pero no puede, sobre bases racionales claras, pretender que se realice cualquier deseo. Platón propone acordar en que lo dicho acerca de su ciudad y de su forma de gobierno "no son en modo alguno expresiones de deseo, sino cosas difíciles pero posibles en cierto modo" (Rep. 540d1-3: $\chi \alpha \lambda \varepsilon \pi \grave{\alpha}$

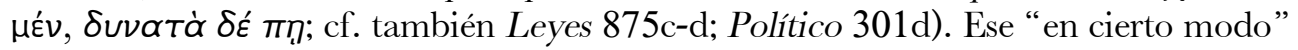
seguramente se refiere a la manera que ya se ha mencionado varias veces a esta altura del debate: cuando se cumplan las leyes o previsiones fundamentales de su régimen político. Los filósofos-gobernantes son quienes desprecian los honores por considerarlos disvaliosos e indignos de hombres libres: "lo justo es lo más importante y más necesario" (540e1-2). Eso bastaría, según Platón, para asegurar una correcta organización política y un buen gobierno, sin importar las leyes o normas que regulen situaciones concretas.

No deja de ser notorio el hecho de que en la Rep. no haya una discusión sistemática de la noción de ley ni que haya un código legal fundamental al modo de

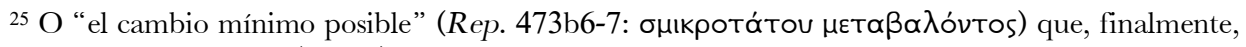
resulta no ser tan pequeño $(473 \mathrm{c} 3)$. 
una constitución formal26. Platón expresamente dice que si quienes van a gobernar reciben una buena educación y llegan a ser moderados, descubrirán fácilmente todo lo relativo a lo que tiene que ver con situaciones que exijan la presencia de leyes específicas (como las que regulan las injurias, demandas judiciales, elección de jueces, derechos de compra y venta en transacciones comerciales, vigilancia en las calles, etc.), y que no habría que legislar sobre estas cosas ni sería digno poner prescripciones a "los hombres nobles y buenos" (Rep. 423e; 425d). La idea de Platón parece ser que cuando la inteligencia filosófica coincida con la política, el gobierno de los filósofos será mucho mejor que el que, de hecho, hay en las sociedades reguladas por sistemas legales en los que todas esas relaciones humanas son ordenadas por leyes concretas (leyes tabuladas en prolijos códigos que, sin embargo, en manos de personas incompetentes y corruptas resultan completamente ineficaces). En efecto, el gobierno de los filósofos es el gobierno del conocimiento, y "conocimiento" no es sólo la capacidad de entender el contenido teórico-prescriptivo de la ley, sino también la manera en que dicho contenido se aplica con sensatez a las situaciones concretas de acción ${ }^{27}$.

Es claro que, según Platón, la propia medida de bondad o justicia está determinada por la propia proximidad a la bondad y justicia absolutas representadas por el dios. Evocando irónicamente la sentencia protagórea, quiere argumentar que dios es de modo preeminente la medida de todas las cosas más que cualquier persona ${ }^{28}$. Desde luego, Platón tenía la certeza de que los bienes humanos y el bien (o "lo absolutamente bueno"; Filebo 61a1-2) no pueden identificarse. A pesar del hecho de que el estándar más elevado del bien es la Forma del Bien, está interesado en señalar que la persona justa será justa en el sentido habitual de mantener un juramento, no robar, no traicionar a sus amigos, no cometer adulterio, evitar faltar el respeto a los padres y descuidar a los dioses (Rep. 442e-443b). Pero lo que quizá es más importante es que Platón indica que la norma legal se encuentra, en cierto modo, subordinada a la persona que sabe lo que es la justicia para la ciudad, donde ese "saber" no es sólo el conocimiento teórico del contenido normativo de la ley, sino también el conocimiento que habilita al legislador a aplicar correctamente la ley a la situación concreta. Lo mejor, entonces, no puede ser que "las leyes prevalezcan", sino que prevalezca "la persona regia que posee sabiduría o inteligencia” (Político 294a7-8). La observación importante de Platón es que la ley, como una persona ignorante, alcanza una simplicidad que no cuadra con los

\footnotetext{
${ }^{26}$ Cf. LaKs 2007, cap. 5.

${ }^{27}$ En el siguiente párrafo desarrollo, de un modo ligeramente diferente, lo que he argumentado antes en BOERI 2013.

${ }^{28}$ Cf. Leyes 716c4-5; véase también Teeteto 176b-c, donde se adelanta la idea. Como es obvio, Platón está corrigiendo la tesis, presuntamente protagórea, del homo mensura (Teeteto 152a23; Crátilo 385e4-386a4).
} 
asuntos humanos (la ley es simple y constante, los asuntos humanos no lo son). Ésa es la razón por la cual la ley en sí misma es inútil sin una persona que posea el conocimiento o la sensatez necesaria que le permitiría aplicar la ley a los casos particulares de acción (Político 294b-c). Este argumento es parte de un momento central del Político, no de la Rep., pero la idea concuerda muy bien con el supuesto implícito de este último diálogo y con la declaración explícita de Leyes 875c-d: no hay ley ni ordenación alguna que sea superior al conocimiento, y el conocimiento es un estado anímico que posee una persona concreta que sabe, en sentido teórico y práctico, qué es la ley.

Creo que estos pasajes (y otros similares) muestran que si el modelo platónico de sociedad justa es una "utopía" no lo es porque Platón adhiera a la tesis de que es irrealizable. Cuando Glaucón le advierte a Sócrates que no se librará de decirle de qué modo es posible que exista el régimen político del que ha estado hablando ( $R e p$.

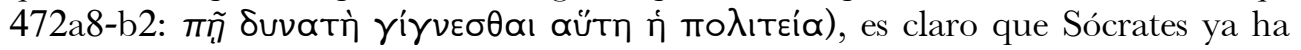
admitido que su existencia es posible (Rep. 457a). El problema entonces no es si es posible, sino cómo lo es. En Leyes 746b-c, en un contexto de discusión similar, Platón enfatiza que "al que le sea imposible llevar a cabo algo, debe dejarlo y no hacerlo"; es evidente que ni el Sócrates de República ni el ateniense de Leyes están dispuestos a dejar de lado su proyecto; una vez más, este tipo de observación elimina la idea de que Platón piense que su modelo es "irrealizable", pero si es realizable, hay que ver de qué modo es realizable o posible.

3. El modelo de ciudad buena, su posibilidad y el recurso al modelo como dispositivo explicativo

Mi propósito en este apartado es examinar el breve pero significativo pasaje de Rep. V 472b-473c, en el que Platón explícitamente enfrenta el problema de la realizabilidad de su modelo o paradigma ( $\pi \alpha \rho \alpha ́ \delta \varepsilon ı \gamma \mu \alpha)$ filosófico-político. Argumentaré (i) que Platón es consciente de la imposibilidad de realizar el modelo o paradigma (si por "realizar el modelo" se entiende llevarlo a la práctica tal y como se lo enuncia en el lógos); también sugeriré que (ii), no obstante eso, no hay, según Platón, ninguna explicación que pueda prescindir de postular un modelo y, finalmente, (iii) que hay una manera razonable de conectar el "modelo irrealizable" con la realidad fáctica. El objetivo de esta discusión tiene un alcance modesto; no obstante, espero poder contribuir a mostrar el sentido en que puede argumentarse que es un procedimiento platónico fundamental el postular modelos explicativos que, aun cuando no pueden llevarse a la práctica en los mismos términos en que se los postula, resultan imprescindibles en el marco de cualquier explicación de una teoría.

El pasaje de Rep. V recién mencionado puede articularse de la siguiente manera: (a) lo que se estaba investigando es qué es la justicia; a propósito de esa indagación, 
se estableció que no es que el justo en nada deba diferenciarse de la justicia misma (es decir, no es que uno es justo si no se diferencia en nada de la justicia). Este primer punto del argumento muestra por qué no es necesario postular una "Forma de polis o de politeía” para entender la explicación, sino que basta con la Forma de justicia (cf. supra n.2). Si esto es así, (b) puede decirse que una persona es justa si se aproxima lo más posible a la justicia y participa de ella más que las demás

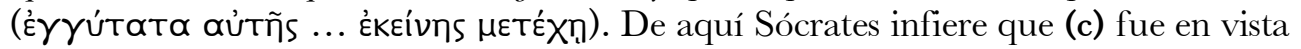
de un modelo que se estaba investigando qué es la justicia y qué es la persona completamente justa ("en caso de que existiera, y cómo sería si existiera"; 472c5-6). Entonces, si se acepta esta restricción (i.e. una persona es justa si se aproxima lo más posible a la justicia), hay que reconocer que quien fuera lo más semejante (472d1: ómoı́́tatos) a la felicidad y la infelicidad, estaría más próximo a un estado o el otro. Pero (d) el propósito no era demostrar que era posible que la justicia misma y la persona perfectamente justa "existan". Pero eso no es un problema, pues tal como nadie diría que quien pintara el modelo de cómo sería la persona más bella pero no fuera capaz de demostrar que dicha persona exista es en menor medida un buen pintor, así también tampoco puede decirse que, por el hecho de que se está produciendo con el discurso un modelo de la ciudad buena (472d9-e4:

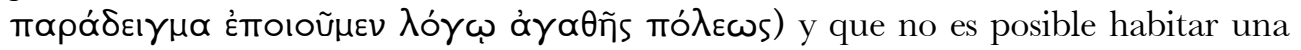

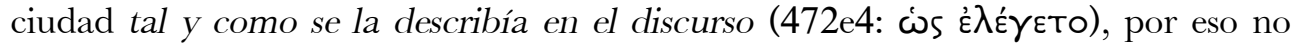
puede alegarse que no se está argumentando correctamente. Entonces, (e) además de las razones provistas por la analogía del pintor, parece que no es posible llevar a cabo algo tal y como se lo describe en el discurso, porque la acción (o "práctica":

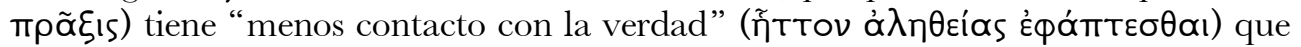
el discurso (473a1-2) ${ }^{29}$. Si algo es modelo $(M)$ de otra cosa (y), $M$ no puede llevarse a cabo en $y$ (concretarse, practicarse) tal y como se lo describe en el argumento o explicación. Si fuera posible, el modelo dejaría de ser modelo y habría que buscar otro modelo para explicar lo que se está discutiendo. Por tanto, (f) no se nos debe forzar a que lo que describimos en el discurso deba ocurrir en la práctica "absolutamente" tal y como se lo expuso en el discurso. Pero si se puede descubrir cómo una ciudad se aproxima lo más posible a la que se ha mencionado que se podría fundar, debe decirse que se ha descubierto cómo es posible la ciudad buena de la que se ha hablado.

El pasaje muestra no sólo que Platón advierte la dificultad que la realización de su ciudad justa puede tener, sino también su esfuerzo por mostrar qué quiere decir por "posible". Con cierta frecuencia Platón asimila sus Formas o Ideas a modelos; se

29 "Verdad" aquí debe tener el sentido ontológico de "lo que realmente es", como diferente de lo que se parece a lo que realmente es. La acción, la práctica es una réplica de un original y, como tal, sólo puede asemejarse al original (cf. Platón, Sofista 240a8-b9). 
trata de una tesis que parece no abandonar nunca. El recurso al modelo está presente en el Teeteto, pero también en Leyes 739d3-e7. Aunque uno acepte la advertencia de Burnyeat de que no hace falta suponer una Forma de polis, sino que basta con la Forma de justicia (esto es, la "realización” de la ciudad buena es la ejemplificación de la Forma de justicia), la tesis platónica de la diferencia ontológica entre el modelo y su copia se mantiene. La ciudad justa no será más que una ejemplificación de la Forma de justicia y, por muy buena que sea esa ejemplificación, no deja de ser una copia. Para dar cuenta de algo se requiere de un modelo, pues el modelo suministra las condiciones normativas de la correcta elaboración de lo que se quiere hacer. Si el modelo tiene un carácter normativo (pues dice lo que hay que hacer para que el producto sea bueno), dicho modelo es normativo de lo que es mejor. Pero si esto es así, el modelo no es realizable empíricamente, pues si lo fuera lo realizado replicaría de manera idéntica "lo mejor". Pero en ese caso, no podría distinguirse entre modelo, por una parte, y copia, por la otra; tampoco podría diferenciarse lo que es mejor de lo que no lo es. La relación "mejor/peor que" presupone que entre los relata haya una diferencia esencial. Además, nada garantiza que la realización empírica del modelo sea (o pueda ser) mejor que el modelo; la "realización fáctica" del modelo, en realidad, no verifica ni falsea el modelo. Aunque hay o puede haber una cierta simetría entre modelo y copia, esa simetría no es más que una semejanza entre ambos, pero en estricto rigor no son sistemas isomórficos. Solamente se pueden advertir grados de semejanza o, como dice Platón, de “aproximación” entre la réplica y su modelo. Es por eso que no hay ningún modelo que sea realizable exactamente en los mismos términos en que se lo describe en la teoría.

Ésa es la afirmación explícita que Platón hace en el pasaje de Rep. 472-473 que he esquematizado arriba, pero es una tesis que se encuentra en otras obras de Platón. Por ejemplo, cuando el demiurgo del Timeo construye el cosmos, mira las Formas, de las que se sirve como de sus modelos (28a6-b2). El universo es una "imagen generada de los dioses eternos" y el artesano intenta que sea lo más semejante posible

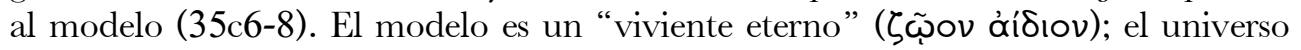
(тò Trãv), que es una entidad corpórea "concreta", puede asemejarse lo más posible al modelo (gracias al esfuerzo del demiurgo de que así sea). Pero la naturaleza del viviente es eterna, y esta cualidad no se le puede conferir completamente a lo generado $(37 \mathrm{~d} 4)$. Éste es un modo de decir que lo generado no puede replicar exactamente el modelo: aunque hay una cierta simetría entre el modelo y su copia (lo generado se parece al modelo), también hay una asimetría estructural entre ellos: el modelo es eterno, la copia es cambiante. Las ejemplificaciones empíricas de "lo igual" son "iguales" a sus modelos, pero no del mismo modo en que lo es aquello que por sí mismo es igual, ya que tales ejemplificaciones siempre "se quedan cortas 
en alguna medida" (Fedón 74d6-7; cf. 74d-e) y son siempre inferiores a aquello de lo cual son copia.

\section{Observaciones conclusivas}

Una clave decisiva para entender la "utopía platónica" es aclarar qué significa "posible" cuando ese predicado se aplica a la ciudad ideal platónica. De acuerdo con mi argumentación general, el sentido de "posible" en el que está pensando Platón se comprende si se lo asocia a la tesis de que la ciudad justa es un modelo. Si la ciudad platónica es un modelo y si el modelo coincide con la Forma de justicia (que se ejemplifica en la ciudad empírica que de hecho puede darse), lo que se da en "la realidad" no puede ser más que una "aproximación" al modelo. Se trata de la explicación habitual de Platón cuando relaciona el modelo con su copia o réplica: aunque modelo y copia son estructuras que, hasta cierto punto, guardan cierta simetría, no son completamente isomórficas. Si lo fueran, el modelo no podría distinguirse de la copia. En este sentido básico la ciudad buena de Platón es irrealizable; pero, a la vez, es realizable porque el único modo en que puede darse un modelo es como una copia, la cual nunca puede ser idéntica a su modelo.

\section{Bibliografía}

Annas, J. (1985), An Introduction to Plato's Republic, Oxford.

Annas, J. (1997), «Politics and Ethics in Plato's Republic», en O. Höffe (hsgs.), Platon. Politeia, Berlin, 105-120.

Annas, J. (1999), Platonic Ethics, Old and New, Ithaca and London.

Bloom, A. (1991), The Republic of Plato, Translated with Notes with an Interpretative essay by A. Bloom, New York.

Boeri, M.D. (2013), «Natural Law and world order in Stoicism», en G. Rossi (ed.), Nature and the Best Life. Exploring the Natural Bases of Practical Normativity in Ancient Philosophy, Hildesheim-Zürich-New York, 183-223.

Burnyeat, M. (1999), «Utopia and Fantasy: The Practicability of Plato's Ideally Just City», en G. Fine (ed.), Plato 2. Ethics, Politics, Religion and the Soul, Oxford: Oxford, 297308.

Davis, J.G. (1985), Utopía y la sociedad ideal. Estudio de la literatura utópica inglesa, 15161700 (trad. esp.), México.

Eggers Lan, C. (1986), Platón, Diálogos. IV, República, Introducción, traducción y notas de C. Eggers Lan, Madrid.

Ferrari, F. (2012), «Il passato come pharmakon in Platone: la kallipolis e l'Atene del tempo di Atlantide», en Lisi (2012), 99-112.

Klosko, G. (2006), The Development of Plato's Political Theory, Oxford.

Koyré, A. (1945), Discovering Plato, New York. 
Kraut, R. (2010), «Ordinary Virtue from the Phaedo to the Laws», en C. Bobonich (ed.), Plato’s Laws. A Critical Guide, Cambridge, 51-70.

Laks, A. (2007), La filosofía política de Platón a la luz de las Leyes, Mérida.

Laks, A. (2012), «Temporalité et utopie: remarques herméneutiques sur la question de la possibilité des cités platoniciennes», en Lisi (2012), 19-37.

Lisi, F.L. (ed.) (1999), Platón, Diálogos. VIII, Leyes (Libros I-VI), Introducción, traducción y notas, Madrid.

Lisi, F.L. (ed.) (2012), Utopia, ancient and modern. Contributions to the history of a political dream, Sankt Augustin.

Lisi, F.L. (2012a), «From the Republic to Utopia. Political Thought between Fiction and Reality», en Lisi (2012), 7-17.

Lisi, F.L. (2012b), «La República de Platón y su recepción en el pensamiento utópico», en Lisi (2012), 79-98.

Logan, G.M. (1983), The Meaning of More's “Utopia”, Princeton.

Popper, K. (1947), The Open Society and its Enemies. The Spell of Plato, I, London.

Reeve, C.D.C. (2004), Plato. Republic, Indianapolis-Cambridge.

Rosen, S. (2005), Plato's Republic. A Study, New Haven-London.

Schofield, M. (2006), Plato. Political Philosophy, Oxford.

Starnes, C. (1990), The New Republic. A Commentary of Book I of More's Utopia showing its Relation to Plato's Republic, Ontario.

Strauss, L. (1964), The City and Man, Chicago-London.

Vegetti, M. (2000), «Lo statuto dell'utopia nella Repubblica», en M. Vegetti (ed.), Platone, La Repubblica, IV, Libro V, Napoli, 107-147.

Vegetti, M. (2013), «How and why did the Republic become unpolitical?», en N. Notomi, L. Brisson (eds.), Dialogues on Plato's Politeia (Republic). Selected Papers from the Ninth Symposium Platonicum, Sankt Augustin, 3-15.

Zuolo, F. (2012), «Plato's Political Idealism and Utopia in the Republic, the Laws, and the Timaeus-Critias», en Lisi (2012), 39-60. 